\title{
Discrimination and Mental Health: Mediation Effects of Coping Strategies in LGB and Heterosexual Youth
}

\section{Discriminación y Salud Mental: Efectos de Mediación de las Estrategias de Afrontamiento en Jóvenes LGB y Heterosexuales}

\author{
Daniela Fonseca de Freitas ${ }^{1,2}$, Cláudia Silva ${ }^{3}$, and Susana Coimbra ${ }^{3}$ \\ ${ }^{1}$ Institute of Psychiatry, Psychology and Neuroscience, King's College London \\ 2 Center for Psychology at University of Porto (CPUP) \\ ${ }^{3}$ Faculdade de Psicologia e de Ciências da Educação, Universidade do Porto
}

\begin{abstract}
Previous studies reveal that the negative effect of discrimination on mental health is particularly pernicious among stigmatised minorities. However, research also points out the importance of protection mechanisms that may buffer its effect. This study aimed to explore the relationships between mental health, perceived discrimination, and coping strategies of positive reframing and self-blame in LGB and heterosexual youth. Data were collected through a paper and pencil and an online survey administered to 195 Portuguese adolescents and young adults. The survey covered mental health (Mental Health Inventory-5), discrimination (Everyday Discrimination Scale), and coping strategies (Brief COPE). Of the sample, $73.3 \%$ were women and $51.8 \%$ self-identified as lesbian, gay or bisexual (LGB). Analyses of variance show that LGB participants have experienced more discrimination than their heterosexual counterparts. There was no difference in the levels of mental health and the use of self-blame or positive reframing coping strategies. Regression analyses reveal that perceived discrimination and self-blame contribute to the worsening of the mental health of LGB and heterosexual youth. Positive reframing coping was a predictor of mental health only in LGB participants, a strategy that contributed to their resilience in the face of discrimination. Additionally, only LGB participants displayed an indirect effect of discrimination on mental health, partially mediated by self-blame coping. Results corroborate previous findings that suggest that perceived discrimination has a more deleterious effect for members of a minority group and support the psychological mediation framework regarding the effect of discrimination on mental health in stigmatised groups.
\end{abstract}

Keywords: mental health, discrimination, sexual orientation, protection mechanisms, mediation

Estudios previos revelan que el efecto negativo de la discriminación en la salud mental puede ser especialmente perjudicial entre las minorías estigmatizadas. Sin embargo, las investigaciones también destacan la importancia de los mecanismos de protección que podrían amortiguar este efecto. El objetivo de este estudio fue explorar las relaciones entre la salud mental, la percepción de discriminación y las estrategias de afrontamiento de reevaluación positiva y autoculpa en jóvenes LGB y heterosexuales. Los datos fueron recogidos online y mediante una encuesta en papel y lápiz y participaron 195 adolescentes y jóvenes adultos portugueses. La encuesta abarcó salud mental (Mental Health Inventory-5), discriminación (Everyday Discrimination Scale) y estrategias de afrontamiento (Brief COPE). De la muestra, el $73,3 \%$ eran mujeres y el $51,8 \%$ se identificaron a sí mismos como lesbiana, gay o bisexual (LGB). Los resultados del análisis de la varianza muestran que los participantes LGB han experimentado más discriminación que sus compañeros heterosexuales. No hay diferencias en los niveles de salud mental y el uso de la autoculpa o la revaluación positiva en las estrategias de afrontamiento. Los análisis de regresión revelan que la discriminación y la autoculpa percibidas contribuyen a empeorar la salud mental de los jóvenes LGB y heterosexuales. Sin embargo, las estrategias de revaluación positiva fueron predictoras de salud mental solo en los participantes LGB, una estrategia que contribuyó a su resiliencia frente a la discriminación. Además, se observó un efecto indirecto de discriminación en la salud mental, parcialmente mediado por la autoculpa, solo en los participantes LGB. Los resultados confirman hallazgos previos que sugieren que la discriminación percibida tiene un efecto más perjudicial cuando se produce en un grupo minoritario, y apoya el encuadre de la mediación psicológica sobre los efectos de la discriminación en la salud mental en grupos estigmatizados.

Palabras clave: salud mental, discriminación, orientación sexual, mecanismos de protección, mediación

Daniela Freitas iD https://orcid.org/0000-0002-8876-4595

Susana Coimbra iD https://orcid.org/0000-0002-7738-4757

This work was supported by the fellowships awarded to the first author by the Portuguese Science Foundation (SFRH/BD/79575/2011) and the International Students' USP Grant Program (2014.1.3765.1.1). Additionally, this work was supported by funds attributed to the Centre for Psychology at the University of Porto by the Portuguese Science Foundation (CPUP UID/PSI/00050/2013; FEDER/COMPETE2020 POCI-01-0145-FEDER- 007294).

Correspondence concerning this article should be addressed to Daniela Fonseca de Freitas, Institute of Psychiatry, Psychology and Neuroscience, King's College London, De Crespigny Park, Denmark Hill, London, SE5 8AF, United Kingdom. Email: daniela.fonseca_de_freitas@gmail.com 
FREITAS, SILVA, AND COIMBRA

\section{Discrimination and Mental Health: Protection Mechanisms in LGB and Heterosexual Youth}

Lesbian, gay, or bisexual (LGB) individuals experience higher levels of peer victimisation and discrimination than heterosexual individuals (Berlan et al., 2010; Fedewa \& Ahn, 2011; Mustanski et al., 2016; Williams et al., 2005). Furthermore, the consequences of these forms of social violence are more harmful to these young individuals relative to those observed in heterosexual youth (Russell et al., 2012; Schmitt et al., 2014). Literature review studies have shown that LGB individuals, compared to their heterosexual counterparts, exhibit higher levels of depression, anxiety, alcohol and drug use, eating disorders, posttraumatic stress symptoms, suicide ideation, and suicide attempts (King et al., 2008; Plöderl \& Tremblay, 2015). Thus, it seems important to understand which specific protection mechanisms are inherent to the manifestation of resilience among sexual minority groups and if those mechanisms and processes differ from the ones observed among the sexual majority. The present study sought to verify the relationship between perceived discrimination and the mental health of young people who self-identify as LGB or heterosexual. Specifically, the possible moderating effect of sexual orientation on mental health predictors was analysed and the mediating effect of coping strategies on the relationship between discrimination and mental health was investigated.

\section{Resilience: Definition and General Considerations}

Resilience occurs when individuals benefit from personal resources and other protective factors, which allow them to show a positive adjustment despite being exposed to a considerable amount of risk (Coimbra $\&$ Fontaine, 2015; Luthar et al., 2000; Masten, 2001, 2014). There is no universal definition of resilience, but there is some consensus that its study concerns three key concepts: the risk/adversity being studied (e.g., discrimination), the adjustment indices related to the specific risk/adversity (e.g., mental health), and protection mechanisms that ameliorate the effect of that risk/adversity (e.g., coping strategies).

Risk represents an increased probability of a negative outcome for a specific group. The cumulative cooccurrence of adverse life events is often studied in resilience research, especially among children and youth (Masten, 2014). Discrimination is an important risk factor for the psychological adjustment of individuals from minority groups (Freitas, Coimbra, Fontaine, \& Marturano, 2017; Russell et al., 2012). It typically jeopardises individuals' sense of security and sense of belonging, decreases self-esteem and satisfaction with life, and is associated with higher levels of depression (Schmitt et al., 2014).

Resilience research is no longer solely interested in the variation of adjustment under the same risky situations, but also in clarifying the processes that account for that variation to inform tailored intervention strategies (Masten, 2014). These processes are called protection mechanisms and can be internal (intrapersonal features) or external (familiar and extra-familiar resources; Masten, 2014; Masten \& Tellegen, 2012; Werner \& Smith, 1992, 2001). The specific nature of protection mechanisms and resilience process among LGB youth ought to be explored (Freitas, Coimbra, \& Fontaine, 2017; Kwon, 2013; Lira \& Morais, 2018; Meyer, 2015; Saewyc, 2011). In this study, LGB youth were considered to be resilient if they displayed a similar level of mental health, even when confronted with higher levels of perceived discrimination, compared to heterosexual youth. Additionally, in this study, the protective function of two coping strategies, self-blame and positive reframing, was investigated. These coping mechanisms were deemed to have a protective effect if the infrequent use of the former or the frequent use of the latter contributed to the promotion of mental health in the presence of discrimination.

\section{Discrimination and Protection in LGB Individuals}

Several studies and systematic reviews of the literature reveal higher levels of mental health problems in LGB youth, including depression, anxiety, substance consumption, suicide ideation, and suicide attempts (D'Augelli, 2002; Espelage et al., 2008; Kuyper et al., 2016; Plöderl \& Tremblay, 2015). Discrimination is a critical risk mechanism for LGB individuals. The victimisation of LGB individuals is the result of heterosexist and heteronormative prejudice and manifests itself in situations of physical, verbal, and sexual violence (Katz-Wise \& Hyde, 2012). This socially and culturally informed perspective suggests that individuals who belong to sexual minorities suffer a twofold impact, as they experience cultural victimisation-the effect of living in a heterosexist society - and direct victimisation-everyday situations of discrimination-, with the latter being more likely (Katz-Wise \& Hyde, 2012). Minority stress theory (Meyer, 2003) poses that, in 
addition to direct experiences of violence driven by social prejudice, other specific situations affect LGB individuals, particularly expectations of rejection, internalised prejudice, and the need to conceal their homosexual or bisexual orientation. Minority stress theory is largely supported by empirical evidence, as studies have shown that these four processes can have a negative impact on mental and physical health (Baams et al., 2015; Frost et al., 2015; Meyer, 2003; Mongelli et al., 2019).

Discrimination, harassment, and peer victimisation contribute to LGB individuals having a poorer psychosocial adjustment and physical health, which may include an increased risk of anxiety, depression, substance use, conduct problems, school isolation, suicide ideation, and suicide attempts (Almeida et al., 2009; Baams et al., 2015; Bontempo \& D'Augelli, 2002; Espelage et al., 2008; Marshal et al., 2011; McLaughlin et al., 2010; Murdock \& Bolch, 2005; Russell et al., 2012; Sanders \& Chalk, 2016; Woodford et al., 2014). Moreover, decreases in self-esteem and satisfaction with life have also been linked to victimisation and a non-supportive LGBT climate (Kwon \& Hugelshofer, 2010; Russell et al., 2014). Living in a heteronormative environment may cause enormous suffering for LGB individuals due to adverse reactions toward their sexual orientations and the fact that their sexual identity may not fit the norms (Carneiro, 2006). Consequently, such a context may lead LGB individuals to internalise and accept that their suffering is legitimate (Gato et al., 2011). Discrimination is also related to internalised homonegativity and an increase in sensitivity to rejection (Feinstein et al., 2012). In turn, internalised homophobia is related to higher use of maladaptive coping strategies, such as self-blame, which is associated with psychological distress (Kaysen et al., 2014).

Given the observed increases in victimisation and health inequality, several studies have focused on examining the protection mechanisms of LGB individuals (Eisenberg \& Resnick, 2006; Freitas, Coimbra, \& Fontaine, 2017; Kwon, 2013; Kwon \& Hugelshofer, 2010; Lira \& Morais, 2018; Meyer, 2015; Saewyc, 2011). Systematic literature reviews emphasise the importance of both internal mechanisms, such as positive selfefficacy and evaluation of sexual orientation, and external mechanisms, such as acceptance of sexual orientation by family members or affiliation with the LGB, transgender, and queer (LGBTQ) communities (Freitas, Coimbra, Fontaine, \& Marturano, 2017; Lira \& Morais, 2018; Saewyc, 2011). Among LGBT youth, there is also an emphasis on community-based resilience (Meyer, 2015). This includes resources such as access to an LGBT community centre, specialised clinical aid, policy changes following the demands of activist groups (e.g., same-sex marriage), establishing strong relationships with other LGBTQ and intersex (LGBTQI) individuals, and finding positive role models (Meyer, 2015).

Coping strategies are crucial internal protection mechanisms, since they represent all the efforts that are made to regulate the self and the context in the face of stress and negative emotions associated with adverse life events. They may increase resilience by improving the response to adversity through help-seeking or selfregulation (Masten, 2014). Traditionally, coping strategies have been classified according to various taxonomies, such as strategies focused on the problem or on reducing negative emotions, or coping focused on engagement or disengagement with the stressor (Carver \& Connor-Smith, 2010). They have also been classed as active (e.g., problem-solving and/or accommodating strategies) or passive (e.g., avoidance) (Compas et al. 2012).

A qualitative study conducted with 19 LGB adults (D'haese et al., 2015) revealed that mainly four types of coping strategies are used when facing antigay violence: avoidance, assertiveness and confrontation, cognitive change (including giving meaning to the events), and social support. A quantitative study focused on coping strategies employed by LGBT youth (Toomey et al., 2017) showed that they can be categorised into LGBT-specific (e.g., looking for LGBT services), alternative-seeking (e.g., looking for other friends or another living arrangement), and cognitive (e.g., imagining a better future). Only LGBT-specific strategies were found to be inversely associated with depression (Toomey et al., 2017). In a study with lesbian women (Kaysen et al., 2014), adaptive coping strategies (e.g., social support, rational problem-solving, or active coping and positive reframing) were not found to be associated with psychological distress. On the other hand, nonadaptive coping strategies, which include substance use, emotional disengagement, and self-blame, were predictors of greater psychological distress (Kaysen et al., 2014). Besides, these non-adaptive coping strategies, including self-blame, were found to mediate the negative effect of internalised homophobia on psychological distress (Kaysen et al., 2014).

Studies also show that non-LGB youth are victimised by their peers, and that this victimisation is related to worse mental health and possibly to the use of maladaptive coping (Bucchianeri et al., 2016; McDougall \& Vaillancourt, 2015). Some studies on victimisation by peers, with a presumed majority heterosexual sample, 
reveal that this problem is related to an increase in self-blame, causing the person to ascribe victimisation to internal and stable characteristics (Graham \& Juvonen, 1998; Schacter et al., 2015). This self-blame for victimisation, in turn, enhances depression (Graham \& Juvonen, 1998; Schacter et al., 2015).

Given the aforementioned literature review, to increase knowledge about a process of resilience to discrimination, this study analysed the relationships between perceived discrimination, coping strategies, and mental health in LGB and heterosexual youth. The first hypothesis is that LGB youth face discrimination more often, use self-blame coping more frequently, and display lower levels of mental health than heterosexual youth. The second hypothesis is that discrimination is inversely associated with mental health in both heterosexual and LBG youth, but with greater intensity in the latter. The third hypothesis is that coping strategies mediate the effect of perceived discrimination on mental health for both heterosexual and LGB youth.

\section{Method}

\section{Participants}

The data collection process took place within a broader research project on social victimisation and resilience. As part of this project, 2975 high school students have participated in a paper-and-pencil study and 63 adults have participated in an online survey (see Freitas et al., 2015). For this study, a random sample of heterosexual participants was selected from that larger one. One hundred and sixty-two participants (83.1\%) were students from 24 Portuguese high schools in the metropolitan areas of Lisbon and Oporto; the remaining $33(16.9 \%)$ were young adults (over 18 years of age) who took part in an online study and could live in any Portuguese city. In total, the sample used in this study comprised 195 participants, 143 (73.3\%) of them women and $52(26.7 \%)$ men. The sample comprised 101 (51.8\%) LGB individuals and 94 (48.2\%) heterosexual individuals. Of the LGB group of participants, 58 self-identified as bisexual women, 17 as lesbian, 16 as bisexual men, and 10 as gay men; so, there was a majority of bisexual women in the LGB group of participants. Given the small number of lesbian and gay participants, they were grouped with the bisexual participants. As for age, $132(67.7 \%)$ are adolescents between 14 and 17 years of age, with $63(32.3 \%)$ being young adults between 18 and 29 years of age.

\section{Instruments}

\section{Everyday Discrimination Scale (Freitas et al., 2015; Williams et al., 1997)}

This instrument was used to assess perceived discrimination. The eight-item version adapted for Portuguese youth (Freitas et al., 2015) was used. This version comprises two factors, Unfair treatment (e.g., You are called names or insulted) and Personal rejection (e.g., You receive poorer service than other people at restaurants or stores), each composed of four items (Freitas et al., 2015). Responses to items are given on an ordinal Likert scale ranging from zero to five $(0=$ Never; $5=$ Almost every day $)$. Higher scores denote more discrimination. In the present study, Cronbach's alpha indicated good internal consistency for both factors: unfair treatment $\alpha=0.82$ and personal rejection $\alpha=0.77$.

\section{Mental Health Inventory-5 Items (Marques et al., 2011; Veit \& Ware, 1983)}

This instrument was used to assess mental health levels as an indicator of psychological adjustment (e.g., How much of the time, during the last month, have you felt calm and peaceful?) (MHI-5, adapted by Marques et al., 2011). Responses are given on a five-point Likert-type scale $(1=$ Never $;=$ Almost always $)$. Higher scores denote better health levels. In the present study, the instrument exhibited an excellent internal consistency $(\alpha=0.87)$.

\section{Brief COPE (Carver, 1997; Pais Ribeiro et al., 2004)}

This instrument was used to assess Self-Blame (e.g., I've been blaming myself for things that happened) and Positive Reframing coping strategies (e.g., I've been trying to see it in a different light, to make it seem more positive). Each of these subscales is composed of two items. Responses are given on an ordinal Likerttype scale ranging from one to five $(1=$ Never $/$ rarely; $5=$ Always $)$. Higher scores denote more self-blame and 
more positive reframing coping. In the present study, acceptable internal consistency indices were observed: 0.78 for Self-Blame and 0.79 for Positive Reframing.

\section{Procedure}

The students from Portuguese high schools answered the survey in paper format in their classrooms during school sessions; the remaining participants (young adults) answered the same survey online. The online survey was disseminated in social media and websites of community organisations focused on the wellbeing of the LGBTQI population. No associations were found between the data collection method (paperand-pencil and online) and sexual orientation, $\chi^{2}(1, n=195)=0.120, p=0.729$, or gender, $\chi^{2}(1, n=195)=0.007$, $p=0.931$. However, as anticipated, it was observed that participants who answered the questionnaire online were older, $\chi^{2}(1, n=195)=68.992, p<0.001$.

Participation in the study was anonymous and voluntary. Parents provided written consent and students provided verbal consent. The study received ethical approval from the Ethics Committee of the Faculty of Psychology and Education Sciences of the University of Porto, the National Data Protection Commission (protocol: 355/2013), and the Portuguese Ministry of Education (process: 0352400001) for data collection in schools.

\section{Statistical Analyses}

To compare levels of perceived discrimination, use of the different coping strategies, and mental health between heterosexual and LGB participants, analyses of variance (ANOVA) were used. Pearson's correlations were used to investigate the association between discrimination, coping strategies, and mental health. To identify predictors of mental health separately for each group of participants according to sexual orientation, hierarchical regression models on mental health were run and analysed. The first model included gender $(0=$ women $; 1=$ men $)$, age $(0=$ adolescents $; 1=$ young adults, $18+$ years $)$, and the data collection method used $(0=$ online; $1=$ paper $)$ to control for any possible differences between the samples as a result of how the data were obtained. In the second model, the variables regarding discrimination were added, while the third model incorporated the coping strategy variables. Finally, to analyse how coping strategies-positive reframing and self-blame-mediate between discrimination and mental health, the PROCESS macro (version 3.0; Hayes, 2013) was used. Mediation is the process that occurs when X affects Y through mediator Z. For there to be mediation, X must promote some variation in Z, which, in turn, will create variation in Y (Hayes, 2013). All the continuous variables included in the statistical analysis were mean-centred using the PROCESS macro. Bootstrap, using 5000 samples, was used to estimate 95\% confidence intervals and conditional direct and indirect effects. The PROCESS macro (Hayes, 2015) was used to test simple mediation effects (with Model 4) and moderated mediation effects (with Model 59). In the latter case, all paths of the mediation are tested for a moderation effect of sexual orientation. The index of moderated mediation shows the "difference between the conditional indirect effects in the two groups coded by the moderator variable" (Hayes, 2015, p. 15).

\section{Results}

\section{Mental Health, Perceived Discrimination, and Coping Strategies in LGB and Heterosexual Participants}

ANOVA results revealed that LGB participants experienced higher levels of unfair treatment and more frequent acts of personal rejection than heterosexual participants (Table 1). At the same time, the two groups did not differ in terms of their mental health or their usage of self-blame and positive reframing coping strategies.

In both LGB and heterosexual participants (Table 2), mental health is inversely associated with unfair treatment, personal rejection, and self-blame, and directly correlated with positive reframing. The perceived discrimination dimensions are not related to levels of positive reframing coping in either group. However, when it comes to self-blame coping, only in LGB participants a direct correlation is observed with perceived discrimination. 
Table 1

Mental Health, Unfair Treatment, Personal Rejection, Self-blame coping, and Positive Reframing in LGB and Heterosexual Participants

\begin{tabular}{lccccccc}
\hline \multirow{2}{*}{\multicolumn{1}{c}{ Variable }} & \multicolumn{2}{c}{$\begin{array}{c}\text { LGB } \\
\text { participants }\end{array}$} & \multicolumn{2}{c}{$\begin{array}{c}\text { Heterosexual } \\
\text { participants }\end{array}$} & $F$ & $p$ & Cohen's $d$ \\
\cline { 2 - 5 } & $M$ & $S D$ & $M$ & $S D$ & & & \\
\cline { 2 - 6 } Mental health & 3.11 & 0.90 & 3.25 & 0.86 & 1.23 & 0.270 & \\
Unfair treatment & 1.14 & 1.03 & 0.82 & 0.86 & 5.79 & 0.017 & 0.34 \\
Personal rejection & 1.29 & 1.04 & 1.02 & 0.89 & 3.78 & 0.053 & 0.28 \\
Positive reframing coping & 2.96 & 1.21 & 2.94 & 1.09 & 0.02 & 0.885 & \\
Self-blame coping & 2.87 & 1.21 & 2.60 & 1.11 & 2.61 & 0.108 & \\
\hline
\end{tabular}

Table 2

Relationships Between Mental Health, Perceived Discrimination, and Coping Strategies

\begin{tabular}{lccccc}
\hline \multicolumn{1}{c}{ Variable } & 1 & 2 & 3 & 4 & 5 \\
\hline 1. Mental health & 1 & $-0.357^{* *}$ & $-0.360^{* *}$ & $0.424^{* *}$ & $-0.444^{* *}$ \\
2. Unfair treatment & $-0.248^{*}$ & 1 & $0.616^{* *}$ & -0.175 & $0.266^{* *}$ \\
3. Personal rejection & $-0.349^{* *}$ & $0.703^{* *}$ & 1 & -0.153 & $0.367^{* *}$ \\
4. Positive reframing coping & $0.256^{*}$ & -0.094 & -0.140 & 1 & -0.128 \\
5. Self-blame coping & $-0.460^{* *}$ & 0.159 & 0.195 & $-0.258^{*}$ & 1 \\
\hline
\end{tabular}

Note. ${ }^{*} p<0.05 ;{ }^{* *} p<0.01 ; * * * p<0.001$. Correlations for LGB participants $(n=101)$ are presented above the diagonal and correlations for heterosexual participants $(n=94)$ are presented below the diagonal.

\section{Predictors of Mental Health in LGB and Heterosexual Participants}

The results of the regression analyses, presented in Table 3, show that the predictors of LGB participants' mental health were: gender, with men showing higher mental health levels; the data collection method, where individuals who answered the survey during the school day (on paper) exhibited lower mental health levels; unfair treatment and self-blame, which were inverse predictors of mental health; and, lastly, positive reframing, which was a direct predictor of mental health. Of these variables, the strongest predictors of mental health are positive reframing coping and gender.

Concerning heterosexual participants, results show that the only predictors of mental health are gender, with men exhibiting higher levels of mental health, and personal rejection and self-blame, both of which are inverse predictors of mental health (Table 4). Self-blame was the strongest predictor of mental health. The mental health regression models for both groups indicate that the dimensions included explain a higher proportion of mental health variance for LGB participants than for heterosexual participants (44.3\% versus $31.1 \%)$. 
Table 3

Predictors of Mental Health in LGB Participants

\begin{tabular}{|c|c|c|c|c|c|c|c|c|c|c|c|c|c|c|c|}
\hline \multirow{2}{*}{ Variable } & \multicolumn{5}{|c|}{ Model 1} & \multicolumn{5}{|c|}{ Model 2} & \multicolumn{5}{|c|}{ Model 3} \\
\hline & $B$ & $p$ & $95 \% \mathrm{CI}$ & TO & VIF & $B$ & $p$ & $95 \% \mathrm{CI}$ & TO & VIF & $B$ & $p$ & $95 \% \mathrm{CI}$ & TO & VIF \\
\hline Age (18+ years) & 0.03 & 0.801 & & 0.67 & 1.50 & -0.03 & 0.798 & & 0.63 & 1.61 & -0.06 & 0.560 & & 0.62 & 1.62 \\
\hline Gender (men) & 0.33 & 0.001 & {$[0.29,1.05]$} & 0.99 & 1.01 & 0.34 & $<0.001$ & {$[0.34,1.04]$} & 0.98 & 1.02 & 0.29 & $<0.001$ & {$[0.29,0.91]$} & 0.96 & 1.05 \\
\hline $\begin{array}{l}\text { Data collection method } \\
\text { (paper) }\end{array}$ & -0.24 & 0.041 & {$[-1.08,-0.02]$} & 0.67 & 1.50 & -0.23 & 0.027 & {$[-1.03,-0.06]$} & 0.67 & 1.50 & -0.18 & 0.050 & {$[-0.86,-0.00]$} & 0.66 & 1.52 \\
\hline Unfair treatment & & & & & & -0.25 & 0.028 & {$[-0.42,-0.03]$} & 0.57 & 1.77 & -0.20 & 0.046 & {$[-0.35,-0.00]$} & 0.56 & 1.78 \\
\hline Personal rejection & & & & & & -0.19 & 0.097 & & 0.60 & 1.68 & -0.08 & 0.458 & & 0.56 & 1.80 \\
\hline $\begin{array}{l}\text { Positive reframing } \\
\text { coping }\end{array}$ & & & & & & & & & & & 0.33 & $<0.001$ & {$[0.13,0.36]$} & 0.94 & 1.06 \\
\hline Self-blame coping & & & & & & & & & & & -0.26 & 0.002 & {$[-0.32,-0.07]$} & 0.83 & 1.21 \\
\hline$F$ & \multicolumn{5}{|c|}{$(3,96)=6.246$} & \multicolumn{5}{|c|}{$(5,94)=8.690$} & \multicolumn{5}{|c|}{$(7,92)=12.234$} \\
\hline$p$ & \multicolumn{5}{|c|}{0.001} & \multicolumn{5}{|c|}{$<0.001$} & \multicolumn{5}{|c|}{$<0.001$} \\
\hline$R_{\mathrm{a}^{2}}$ & \multicolumn{5}{|c|}{0.137} & \multicolumn{5}{|c|}{0.280} & \multicolumn{5}{|c|}{0.443} \\
\hline$R^{2} / \Delta R_{\mathrm{a}}{ }^{2}$ & \multicolumn{5}{|c|}{$0.163 / 0.163$} & \multicolumn{5}{|c|}{$0.316 / 0.153$} & \multicolumn{5}{|c|}{$0.482 / 0.166$} \\
\hline
\end{tabular}

Note. 8 = Standardised regression coefficient, TO = Tolerance, VIF = Variance inflation factor, $\mathrm{CI}=$ confidence interval, $R_{\mathrm{a}}{ }^{2}=$ Adjusted $R^{2}, R^{2}=R$ square, $\Delta R_{\mathrm{a}}{ }^{2}=$ Change in the adjusted $R^{2}$.

\section{Table 4}

Predictors of Mental Health in Heterosexual Participants

\begin{tabular}{|c|c|c|c|c|c|c|c|c|c|c|c|c|c|c|c|}
\hline \multirow{2}{*}{ Variable } & \multicolumn{5}{|c|}{ Model 1} & \multicolumn{5}{|c|}{ Model 2} & \multicolumn{5}{|c|}{ Model 3} \\
\hline & $B$ & $p$ & $95 \% \mathrm{CI}$ & TO & VIF & $B$ & $p$ & $95 \%$ CI & TO & VIF & B & $p$ & $95 \%$ CI & TO & VIF \\
\hline Age (18+ years) & -0.08 & 0.573 & & 0.61 & 1.64 & -0.08 & 0.550 & & 0.61 & 1.64 & -0.08 & 0.508 & & 0.58 & 1.72 \\
\hline Gender (men) & 0.20 & 0.061 & & 0.99 & 1.01 & 0.17 & 0.090 & & 0.97 & 1.03 & 0.25 & 0.006 & {$[0.14,0.82]$} & 0.94 & 1.06 \\
\hline $\begin{array}{l}\text { Data collection method } \\
\text { (paper) }\end{array}$ & -0.04 & 0.768 & & 0.61 & 1.65 & -0.02 & 0.859 & & 0.61 & 1.65 & -0.01 & 0.951 & & 0.59 & 1.70 \\
\hline Unfair treatment & & & & & & 0.02 & 0.888 & & 0.50 & 2.02 & 0.05 & 0.690 & & 0.49 & 2.03 \\
\hline Personal rejection & & & & & & -0.35 & 0.013 & {$[-0.60,-0.07]$} & 0.51 & 1.98 & -0.26 & 0.034 & {$[-0.49,-0.02]$} & 0.50 & 2.02 \\
\hline $\begin{array}{l}\text { Positive reframing } \\
\text { coping }\end{array}$ & & & & & & & & & & & 0.13 & 0.173 & & 0.88 & 1.13 \\
\hline Self-blame coping & & & & & & & & & & & -0.43 & $<0.001$ & {$[-0.47,-0.19]$} & 0.88 & 1.14 \\
\hline$F$ & \multicolumn{5}{|c|}{$(3,90)=1.371$} & \multicolumn{5}{|c|}{$(5,88)=3.249$} & \multicolumn{5}{|c|}{$(7,86)=6.991$} \\
\hline$p$ & \multicolumn{5}{|c|}{0.257} & \multicolumn{5}{|c|}{0.010} & \multicolumn{5}{|c|}{$<0.001$} \\
\hline$R_{\mathrm{a}}{ }^{2}$ & \multicolumn{5}{|c|}{0.012} & \multicolumn{5}{|c|}{0.108} & \multicolumn{5}{|c|}{0.311} \\
\hline$R^{2} / \Delta R_{\mathrm{a}}^{2}$ & \multicolumn{5}{|c|}{$0.044 / 0.044$} & \multicolumn{5}{|c|}{$0.156 / 0.112$} & \multicolumn{5}{|c|}{$0.363 / 0.207$} \\
\hline
\end{tabular}

Note. $\mathrm{B}=$ Standardised regression coefficient, TO $=$ Tolerance, VIF = Variance inflation factor, CI = confidence interval, $R_{\mathrm{a}}{ }^{2}=$ Adjusted $R^{2}, R^{2}=R$ square, $\Delta R_{\mathrm{a}}{ }^{2}=$ Change in the adjusted $\mathrm{R}^{2}$. 


\section{Mediation Effects of Coping Strategies in the Relationship Between Discrimination and Mental Health}

The moderated mediation results show that the associations between discrimination, coping strategies, and mental health do not differ between LGB and heterosexual participants in any of the four mediation models tested (Tables 5, 6, 7, and 8). Likewise, moderated mediation index results reveal no differences between LGB and heterosexual participants in terms of indirect effects. The mediation models involving selfblame coping yielded contradictory results. The bootstrap-estimated indirect effects of both unfair treatment and personal rejection on mental health, mediated through self-blame coping, were significant in the group of LGB participants. However, the same indirect effects were not significant in the group of heterosexual participants. These contradictory findings may be due to insufficient statistical power.

Given the contradictory findings observed, the hypotheses of mediation effects of discrimination on mental health via self-blame coping were tested separately for LGB and heterosexual participants. In line with the correlations presented, the results of the moderated mediation involving positive reframing coping show that this coping strategy is not a mediator of the effect of perceived discrimination on mental health, either in LGB or heterosexual participants. Thus, no simple mediation was tested involving this dimension.

The results of the simple mediation models (Tables 9, 10,11, and 12) show that, for heterosexual individuals, self-blame coping does not mediate the effect of perceived discrimination on mental health. In LGB participants, however, self-blame coping functions as a mediator of the influence of both forms of perceived discrimination on mental health. The difference lies in the effect of discrimination on self-blame coping: while perceived discrimination increases the frequency of self-blame coping in LGB participants, in heterosexual participants self-blame coping is not predicted by perceived discrimination. These results are consistent with the raw correlations (Table 2), where no association was observed between self-blame coping and discrimination in the heterosexual participants, while inverse correlations were observed in the LGB participants. Figures 1 to 4 show graphic descriptions of these effects. 
Table 5

Moderated Mediation of Unfair Treatment Effect on Mental Health Through Self-blame Coping

\begin{tabular}{|c|c|c|c|c|c|c|c|}
\hline \multirow{2}{*}{ Variable and effect } & \multicolumn{4}{|c|}{ Self-blame coping } & \multicolumn{3}{|c|}{ Mental health } \\
\hline & $B$ & $S E$ & $p$ & $B$ & $S E$ & $p$ & $95 \% \mathrm{CI}$ \\
\hline Unfair treatment & 0.20 & 0.16 & 0.137 & -0.18 & 0.09 & 0.056 & {$[-0.37,0.06]$} \\
\hline Self-blame coping & - & - & - & -0.33 & 0.07 & $<0.001$ & {$[-0.49,-0.19]$} \\
\hline Sexual orientation & 0.07 & 0.24 & 0.752 & -0.08 & 0.29 & 0.781 & \\
\hline Unfair treatment * Sexual orientation & 0.11 & 0.18 & 0.541 & -0.06 & 0.12 & 0.651 & \\
\hline \multirow[t]{2}{*}{ Self-blame coping * Sexual orientation } & - & - & - & 0.06 & 0.10 & 0.570 & \\
\hline & \multicolumn{3}{|c|}{$\begin{array}{c}R^{2}=0.06, F(3,190)=4.29 \\
p=0.006\end{array}$} & \multicolumn{4}{|c|}{$\begin{array}{c}R^{2}=0.26, F(5,188)=13.12 \\
p<0.001\end{array}$} \\
\hline \multicolumn{8}{|l|}{ Direct effects } \\
\hline LGB participants & \multicolumn{7}{|c|}{ Effect $=-0.23, S E=0.08, p=0.003,95 \% \mathrm{CI}=[-0.39,-0.08]$} \\
\hline Heterosexual participants & \multicolumn{7}{|c|}{ Effect $=-0.18, S E=0.09, p=0.058,95 \% \mathrm{CI}=[-0.36,0.01]$} \\
\hline \multicolumn{8}{|l|}{ Indirect effects } \\
\hline LGB participants & \multicolumn{7}{|c|}{ Effect $=-0.09, S E=0.04,95 \% \mathrm{CI}=[-0.39,-0.03]$} \\
\hline Heterosexual participants & \multicolumn{7}{|c|}{ Effect $=-0.07, S E=0.05,95 \% \mathrm{CI}=[-0.18,0.02]$} \\
\hline \multicolumn{8}{|c|}{ Index of moderated mediation (difference between indirect effects) $=-0.029, S E=0.65,95 \% \mathrm{CI}=[-0.15,0.11]$} \\
\hline
\end{tabular}

Table 6

Moderated Mediation of Personal Rejection Effect on Mental Health Through Self-blame Coping

\begin{tabular}{|c|c|c|c|c|c|c|c|}
\hline \multirow{2}{*}{ Variable and effect } & \multicolumn{4}{|c|}{ Self-blame coping } & \multicolumn{3}{|c|}{ Mental health } \\
\hline & $B$ & $S E$ & $p$ & $B$ & $S E$ & $p$ & $95 \% \mathrm{CI}$ \\
\hline Personal rejection & 0.24 & 0.13 & 0.063 & -0.26 & 0.09 & 0.005 & {$[-0.44,-0.08]$} \\
\hline Self-blame coping & - & - & - & -0.32 & 0.07 & $<0.001$ & {$[-0.46,-0.17]$} \\
\hline Sexual orientation & -0.04 & 0.25 & 0.878 & -0.19 & 0.29 & 0.517 & \\
\hline Personal rejection * Sexual orientation & 0.18 & 0.17 & 0.277 & 0.05 & 0.12 & 0.664 & \\
\hline \multirow[t]{2}{*}{ Self-blame coping * Sexual orientation } & - & - & - & 0.05 & 0.10 & 0.614 & \\
\hline & \multicolumn{3}{|c|}{$\begin{array}{c}R^{2}=0.10 F(3,190)=7.36 \\
p<0.001\end{array}$} & \multicolumn{4}{|c|}{$\begin{array}{c}R^{2}=0.27 F(5,188)=13.73 \\
p<0.001\end{array}$} \\
\hline \multicolumn{8}{|l|}{ Direct effects } \\
\hline LGB participants & \multicolumn{7}{|c|}{ Effect $=-0.21, S E=0.08, p=0.009,95 \% \mathrm{CI}=[-0.37,-0.05]$} \\
\hline Heterosexual participants & \multicolumn{7}{|c|}{ Effect $=-0.26, S E=0.09, p=0.005,95 \% \mathrm{CI}=[-0.44,-0.08]$} \\
\hline \multicolumn{8}{|l|}{ Indirect effects } \\
\hline LGB participants & \multicolumn{7}{|c|}{ Effect $=-0.11, S E=0.04,95 \% \mathrm{CI}=[-0.20,-0.04]$} \\
\hline Heterosexual participants & \multicolumn{7}{|c|}{ Effect $=-0.07, S E=0.05,95 \% \mathrm{CI}=[-0.17,0.02]$} \\
\hline \multicolumn{8}{|c|}{ Index of moderated mediation (difference between indirect effects) $=-0.04, S E=0.62,95 \% \mathrm{CI}=[-0.16,0.09]$} \\
\hline
\end{tabular}


Table 7

Moderated Mediation of Unfair Treatment Effect on Mental Health Through Positive Reframing Coping

\begin{tabular}{|c|c|c|c|c|c|c|c|}
\hline \multirow{2}{*}{ Variable and effect } & \multicolumn{3}{|c|}{ Positive reframing } & \multicolumn{4}{|c|}{ Mental health } \\
\hline & $B$ & $S E$ & $p$ & $B$ & $S E$ & $p$ & CI 95\% \\
\hline Unfair treatment & -0.12 & 0.13 & 0.393 & -0.23 & 0.10 & 0.020 & {$[-0.42,-0.04]$} \\
\hline Positive reframing coping & - & - & - & 0.19 & 0.08 & 0.016 & {$[0.04,0.34]$} \\
\hline Sexual orientation & 0.17 & 0.24 & 0.486 & -0.28 & 0.37 & 0.433 & \\
\hline Unfair treatment $*$ Sexual orientation & -0.09 & 0.18 & 0.620 & -0.04 & 0.13 & 0.756 & \\
\hline \multirow[t]{2}{*}{ Positive reframing coping * Sexual orientation } & - & - & - & 0.09 & 0.10 & 0.384 & \\
\hline & \multicolumn{3}{|c|}{$\begin{array}{c}R^{2}=0.02, F(3,190)=1.38 \\
p=0.249\end{array}$} & \multicolumn{4}{|c|}{$\begin{array}{c}R^{2}=0.20, F(5,188)=9.57 \\
p<0.001\end{array}$} \\
\hline \multicolumn{8}{|l|}{ Direct effects } \\
\hline LGB participants & \multicolumn{7}{|c|}{ Effect $=-0.27, S E=0.08, p=0.001,95 \% \mathrm{CI}=[-0.42,-0.11]$} \\
\hline Heterosexual participants & \multicolumn{7}{|c|}{ Effect $=-0.23, S E=0.10, p=0.020,95 \% \mathrm{CI}=[-0.42,-0.04]$} \\
\hline \multicolumn{8}{|l|}{ Indirect effects } \\
\hline LGB participants & \multicolumn{7}{|c|}{ Effect $=-0.06, S E=0.04,95 \% \mathrm{CI}=[-0.13,0.01]$} \\
\hline Heterosexual participants & \multicolumn{7}{|c|}{ Effect $=-0.02, S E=0.03,95 \% \mathrm{CI}=[-0.08,0.03]$} \\
\hline \multicolumn{8}{|c|}{ Index of moderated mediation (difference between indirect effects) $=-0.04, S E=0.45,95 \% \mathrm{CI}=[-0.13,0.05]$} \\
\hline
\end{tabular}

Table 8

Moderated Mediation of Personal Rejection Effect on Mental Health Through Positive Reframing Coping

\begin{tabular}{|c|c|c|c|c|c|c|c|}
\hline \multirow{2}{*}{ Variable and effect } & \multicolumn{3}{|c|}{ Positive reframing coping } & \multicolumn{4}{|c|}{ Mental health } \\
\hline & $B$ & $S E$ & $p$ & $B$ & $S E$ & $p$ & $95 \% \mathrm{CI}$ \\
\hline Personal rejection & -0.17 & 0.13 & 0.204 & -0.31 & 0.09 & 0.001 & {$[-0.49,-0.13]$} \\
\hline Positive reframing coping & - & - & - & 0.17 & 0.08 & 0.028 & {$[0.02,0.32]$} \\
\hline Sexual orientation & 0.08 & 0.26 & 0.748 & -0.43 & 0.36 & 0.238 & \\
\hline Personal rejection * Sexual orientation & -0.09 & 0.17 & 0.961 & 0.04 & 0.12 & 0.757 & \\
\hline \multirow[t]{2}{*}{ Positive reframing coping * Sexual orientation } & - & - & - & 0.11 & 0.10 & 0.269 & \\
\hline & \multicolumn{3}{|c|}{$\begin{array}{c}R^{2}=0.02, F(3,190)=1.42 \\
p=0.240\end{array}$} & \multicolumn{4}{|c|}{$\begin{array}{c}R^{2}=0.23, F(5,188)=11.21 \\
p<0.001\end{array}$} \\
\hline \multicolumn{8}{|l|}{ Direct effects } \\
\hline LGB participants & \multicolumn{7}{|c|}{ Effect $=-0.27, S E=0.08, p<0.001,95 \% \mathrm{CI}=[-0.42,-0.13]$} \\
\hline Heterosexual participants & \multicolumn{7}{|c|}{ Effect $=-0.31, S E=0.09, p=0.001,95 \% \mathrm{CI}=[-0.49,-0.13]$} \\
\hline \multicolumn{8}{|l|}{ Indirect effects } \\
\hline LGB participants & \multicolumn{7}{|c|}{ Effect $=-0.05, S E=0.04,95 \% \mathrm{CI}=[-0.13,0.02]$} \\
\hline Heterosexual participants & \multicolumn{7}{|c|}{ Effect $=-0.03, S E=0.02,95 \% \mathrm{CI}=[-0.08,0.01]$} \\
\hline \multicolumn{8}{|c|}{ Index of moderated mediation (difference between indirect effects) $=-0.02, S E=0.45,95 \% \mathrm{CI}=[-0.12,0.06]$} \\
\hline
\end{tabular}


Table 9

Mediation Effects of Self-blame Coping Strategies Between Unfair Treatment and Mental Health for LGB Participants

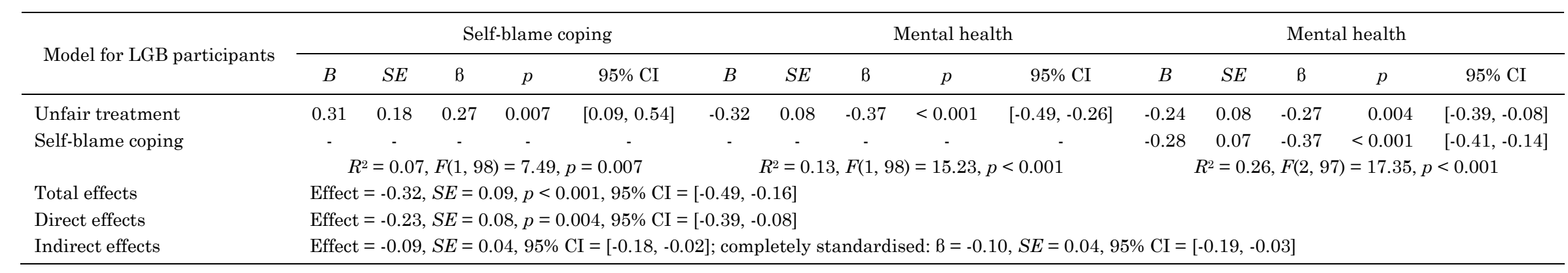

\section{Table 10}

Mediation Effects of Self-blame Coping Strategies Between Personal Rejection and Mental Health for LGB Participants

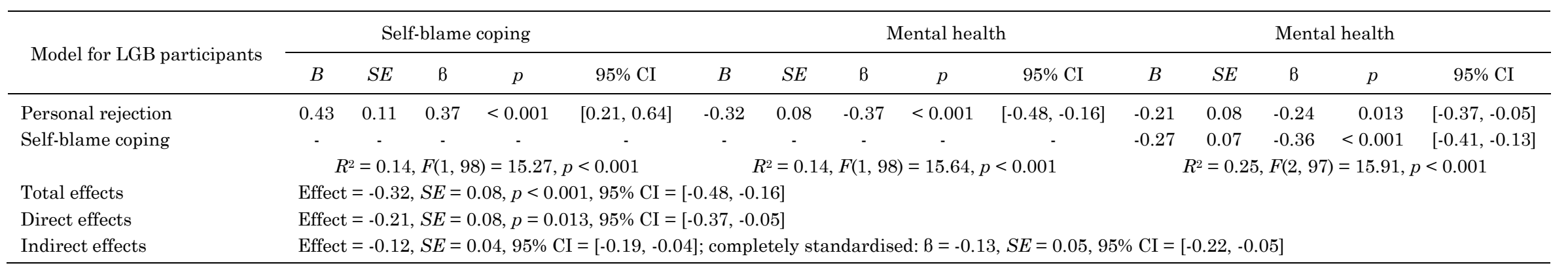




\section{Table 11}

Mediation Effects of Self-blame Coping Strategies Between Unfair Treatment and Mental Health for Heterosexual Participants

\begin{tabular}{|c|c|c|c|c|c|c|c|c|c|c|c|c|c|c|}
\hline \multirow{2}{*}{$\begin{array}{l}\text { Model for heterosexual } \\
\text { participants }\end{array}$} & \multicolumn{4}{|c|}{ Self-blame coping } & \multicolumn{5}{|c|}{ Mental health } & \multicolumn{5}{|c|}{ Mental health } \\
\hline & $B$ & $S E$ & $B$ & $p$ & $B$ & $S E$ & $B$ & $p$ & $95 \% \mathrm{CI}$ & $B$ & $S E$ & $B$ & $p$ & $95 \% \mathrm{CI}$ \\
\hline Unfair treatment & 0.21 & 0.13 & 0.16 & 0.126 & -0.25 & 0.10 & -0.25 & 0.016 & {$[-0.45,-0.05]$} & -0.18 & 0.09 & -0.18 & 0.055 & {$[-0.36,0.004]$} \\
\hline \multirow[t]{2}{*}{ Self-blame coping } & - & - & - & - & - & - & - & - & - & -0.33 & 0.07 & -0.43 & $<0.001$ & {$[-0.48,-0.19]$} \\
\hline & \multicolumn{4}{|c|}{$\begin{array}{c}R^{2}=0.03, F(1,92)=2.38, p= \\
0.126\end{array}$} & \multicolumn{5}{|c|}{$R^{2}=0.06, F(1,92)=6.04, p=0.016$} & \multicolumn{5}{|c|}{$R^{2}=0.24, F(2,91)=14.65, p<0.001$} \\
\hline Total effects & \multicolumn{14}{|c|}{ Effect $=-0.25, S E=0.10, p=0.016,95 \% \mathrm{CI}=[-0.45,-0.05]$} \\
\hline Direct effects & \multicolumn{14}{|c|}{ Effect $=-0.18, S E=0.09, p=0.055,95 \% \mathrm{CI}=[-0.37,0.004]$} \\
\hline Indirect effects & \multicolumn{14}{|c|}{ Effect $=-0.07, S E=0.05$, CI 95\% $=[-0.17,0.03] ;$ completely standardised: $B=-0.06, S E=0.05,95 \% \mathrm{CI}=[-0.17,0.03]$} \\
\hline
\end{tabular}

\section{Table 12}

Mediation Effects of Self-blame Coping Strategies Between Personal Rejection and Mental Health for Heterosexual Participants

\begin{tabular}{|c|c|c|c|c|c|c|c|c|c|c|c|c|c|c|c|}
\hline \multirow{2}{*}{$\begin{array}{l}\text { Model for heterosexual } \\
\text { participants }\end{array}$} & \multicolumn{5}{|c|}{ Self-blame coping } & \multicolumn{5}{|c|}{ Mental health } & \multicolumn{5}{|c|}{ Mental health } \\
\hline & $B$ & $S E$ & B & $p$ & $95 \% \mathrm{CI}$ & $B$ & $S E$ & B & $p$ & $95 \% \mathrm{CI}$ & $B$ & $S E$ & B & $p$ & $95 \% \mathrm{CI}$ \\
\hline Personal rejection & 0.24 & 0.13 & 0.20 & 0.060 & {$[-0.01,0.50]$} & -0.34 & 0.09 & -0.35 & 0.001 & {$[-0.53,-0.15]$} & -0.26 & 0.09 & -0.27 & 0.004 & {$[-0.44,-0.09]$} \\
\hline \multirow[t]{2}{*}{ Self-blame coping } & - & - & - & - & - & - & - & - & - & - & -0.32 & 0.07 & -0.41 & $<0.001$ & {$[-0.46,-0.18]$} \\
\hline & \multicolumn{5}{|c|}{$R^{2}=0.04, F(1,92)=3.62, p=0.060$} & \multicolumn{5}{|c|}{$R^{2}=0.12, F(1,92)=12.80, p=0.001$} & \multicolumn{5}{|c|}{$R^{2}=0.28, F(2,91)=17.89, p<0.001$} \\
\hline Total effects & \multicolumn{15}{|c|}{ Effect $=-0.34, S E=0.09, p=0.001,95 \% \mathrm{CI}=[-0.53,-0.15]$} \\
\hline Direct effects & \multicolumn{15}{|c|}{ Effect $=-0.26, S E=0.09, p=0.004,95 \% \mathrm{CI}=[-0.44,-0.09]$} \\
\hline Indirect effects & \multicolumn{15}{|c|}{ Effect $=-0.08, S E=0.05,95 \% \mathrm{CI}=[-0.18,0.02] ;$ completely standardised: $B=-0.08, S E=0.05,95 \% \mathrm{CI}=[-0.18,0.02]$} \\
\hline
\end{tabular}




\section{Figure 1}

Self-Blame Coping Mediating the Relationship Between Unfair Treatment and Mental Health in LGB Participants

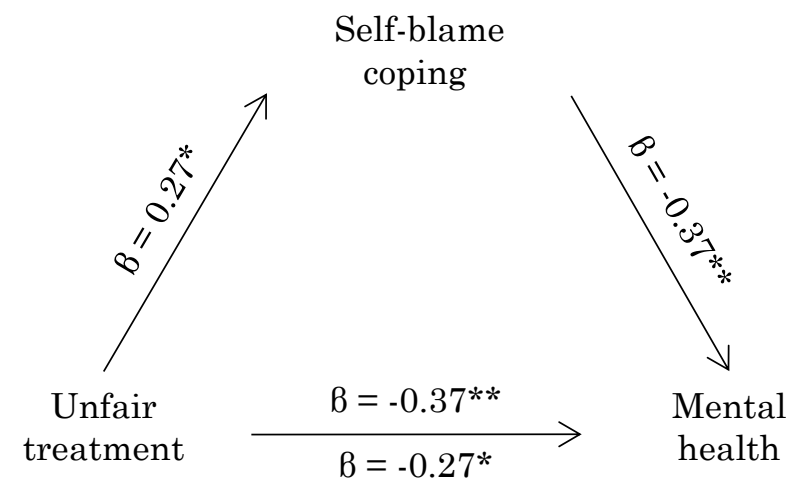

Note. $n=100 .{ }^{*} p<0.01,{ }^{* *} p<0.001$

\section{Figure 2}

Self-Blame Coping Is Not a Mediator of the Relationship Between Unfair Treatment and Mental Health in Heterosexual Participants

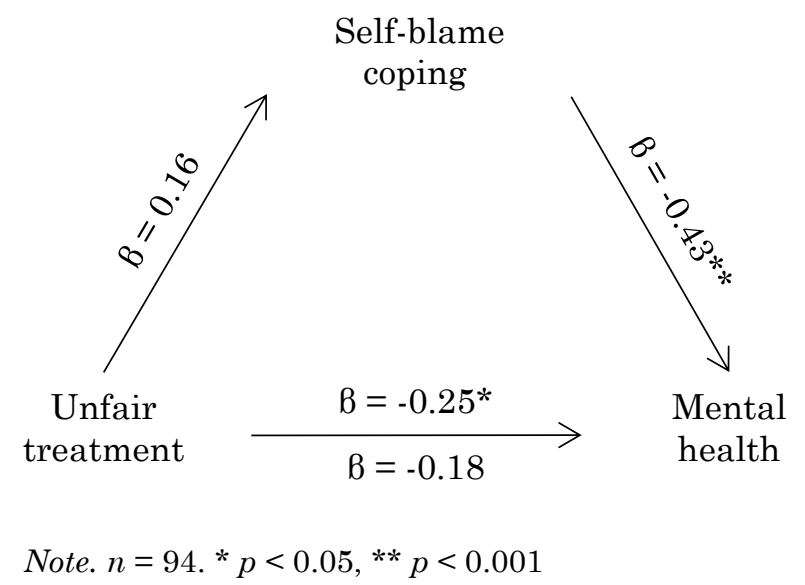




\section{Figure 3}

Self-Blame Coping Mediating the Relationship

Between Personal Rejection and Mental Health

in LGB Participants

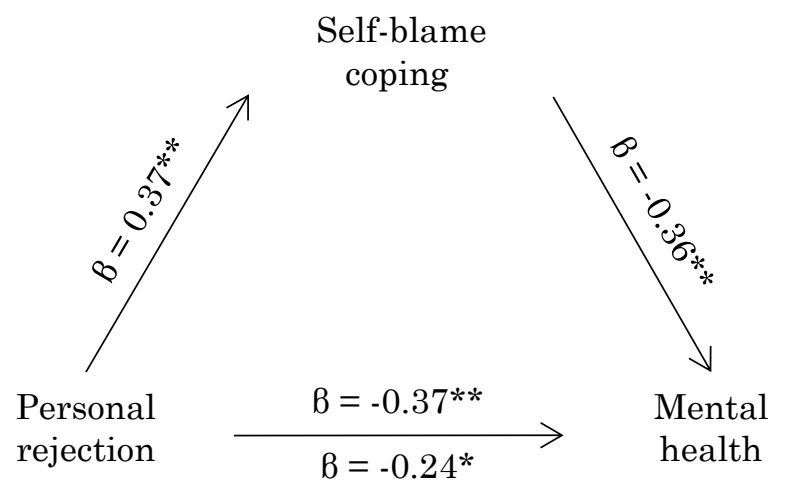

Note. $n=100 .{ }^{*} p<0.05,{ }^{* *} p<0.001$

\section{Figure 4}

Self-Blame Coping Is Not a Mediator of the Relationship Between Personal Rejection and Mental Health in Heterosexual Participants

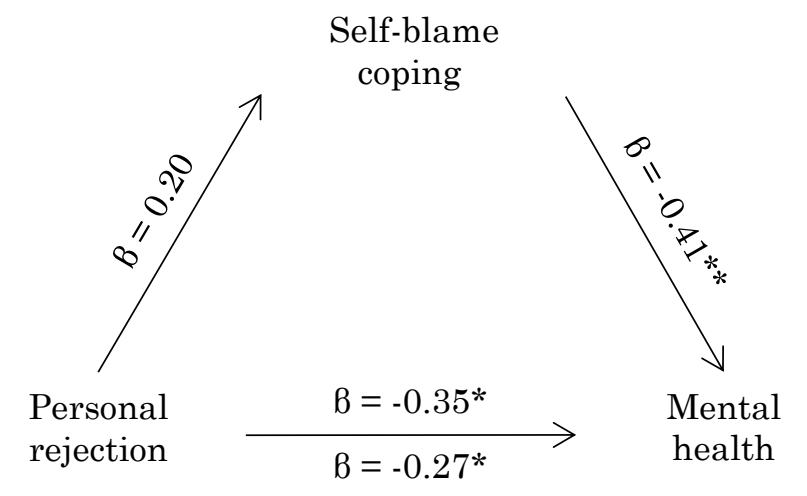

Note. $n=94 .{ }^{*} p<0.01,{ }^{* *} p<0.001$

\section{Discussion}

This study aimed to enrich the understanding of the process of resilience to discrimination among LGB and heterosexual individuals. Specifically, it intended to explore the influence of discrimination (personal rejection and unfair treatment) and internal protection mechanisms (self-blame and positive reframing coping strategies) on psychological adjustment (mental health). Also, it intended to establish whether coping strategies mediate the effect of perceived discrimination on mental health. LGB and heterosexual participants are largely similar in terms of mental health levels and coping strategy use, but LGB participants experienced unfair treatment more frequently. These findings partially confirmed the study's first hypothesis. Perceived discrimination was inversely related to mental health for all participants, but with a higher magnitude in LGB participants, thus confirming the study's second hypothesis. It was also observed that self-blame coping mediated the association between perceived discrimination and mental health only in LGB participants, which partially confirmed the study's third hypothesis. 
Results show that LGB youth experience higher levels of discrimination, which is consistent with literature that reveals higher levels of violence directed to LGB individuals (e.g., Bucchianeri et al., 2014; Katz-Wise \& Hyde, 2012). At the same time, LGB participants did not exhibit lower levels of mental health compared to heterosexual youth. This result was unexpected, given that several studies report lower mental health levels among sexual minority individuals (e.g., Plöderl \& Tremblay, 2015). Showing similar mental health levels while experiencing a higher level of perceived discrimination, which negatively affects LGB participants' mental health, attests to their resilience when facing this form of social violence. This resilience seems to be explained not by differences in the usage level of each coping strategy, but by the protective function that positive reframing coping has in this particular group of participants. This finding is in line with the literature, since a study had already pointed out that cognitive change and giving meaning to negative experiences can reduce the negative effect of discrimination (D'haese et al., 2015).

Each form of discrimination was observed to have a differential effect. In LGB youth, personal rejection is not a predictor of mental health, but unfair treatment (the most frequently reported issue) is. In heterosexual youth, subtle acts of rejection are more likely to affect mental health. Globally, these results are in line with previous studies that show the negative effect of discrimination on mental health (e.g., Russell et al., 2012; Schmitt et al., 2014; Williams et al., 2005).

Coping strategies seem to function as expected, that is, positive reframing, an active accommodating strategy, appears to be protective, while self-blame, a negative passive one, has a pernicious effect on adjustment (Compas et al., 2012; D'haese et al., 2015; Masten, 2014). Coping strategies seem to play an essential role as predictors of mental health, but with important differences between both groups. In LGB youth, both adaptive (positive reframing) and non-adaptive coping (self-blame) are predictors of mental health, but in heterosexual youth only the latter plays this role. Similar to what has been observed in other studies, self-blame is a coping strategy that contributes to poorer mental health (e.g., Kaysen et al., 2014). Additionally, self-blame coping served as a mediator between mental health and perceived discrimination only in LGB youth. This result supports the psychological mediation framework (Hatzenbuehler, 2009), according to which coping strategies mediate the influence of discriminatory events on mental health outcomes. Kaysen et al. (2014) had previously observed that self-blaming coping (as well as other negative coping strategies) are strengthened by internalised homophobia. Concurrently, prior studies with LGB individuals have shown that discrimination increases internalised homophobia and interpersonal sensitivity, which are related to more depression and anxiety (Feinstein et al., 2012).

For LGB youth, positive reframing coping seems to foster mental health even in the presence of discrimination. A prior qualitative study had shown that attributions of meaning to anti-gay violence could buffer to some extent the negative effect of daily minor acts of unfair treatment (D'haese et al., 2015). This is a novel result in quantitative research, as a previous study had found that the use of some cognitive strategies by LGB youth, such as imagining a better future, was associated with worse psychological adjustment and poorer school attainment (Toomey et al., 2017). Although positive reframing was the strongest predictor of mental health in LGB youth, it was not a mediator between mental health and perceived discrimination in any of its forms. This suggests that individuals' ability to find positive aspects under challenging situations is not influenced by perceived discrimination, which is a positive finding, meaning that these LGB participants were able to preserve their ability to see things in a different light in situations of perceived social violence.

Regarding sociodemographic variables, it should be noted that gender appears to be a predictor of mental health in both groups, with boys exhibiting better mental health outcomes. Girls tend to display a higher level of internalized psychological disorders (e.g., depression and anxiety; Rutter et al., 2003). They are also more strongly affected by neuroticism than boys, that is, they exhibit higher levels of anxiety, nervousness, depression, and suicidal ideation (Costa et al., 2001; Pedroso-Lima et al., 2014).

Unexpectedly, the data collection method used was found to be a predictor of mental health: the LGB participants who answered the questionnaire at school (paper format) exhibited poorer mental health. This result is related to the sampling procedure, which involved the dissemination of the online study among LGBT communities. Thus, although this factor was not measured here, participants who responded online may be integrated into LGBT communities. Furthermore, this involvement might provide specific forms of social support, increasing their sense of self-esteem, self-efficacy, and self-control. Studies suggest that membership or connection with these organisations might be directly linked with the well-being of LGB adolescents (Toomey et al., 2017). Integration into LGBT communities can expand members' understanding 
of the world and social relationships and reduce their feelings of alienation and powerlessness to induce change (Carneiro, 2006; Meyer, 2015).

This study is not exempt from limitations. One of them was the use of a broad perceived discrimination self-report instrument. LGB and heterosexual participants may have perceived discrimination for other reasons than sexual orientation, such as socioeconomic status. Nevertheless, LGB participants were found to experience higher levels of discrimination, which is what was expected given their stigmatised status. To attain a better understanding of the relationship between discrimination and mental health in the LGB population, it would be useful to include more specific measures to assess homophobic discrimination and coping strategies aimed at victimisation. Also, women comprised the majority of the sample and, among LGB participants, there was a higher proportion of bisexual women. Thus, the correlations and mediation results may not fully apply to men and non-bisexual women. However, given that gender was controlled for, the regression analyses of the effect of perceived discrimination and coping strategies on mental health were expected to yield similar results for men and women. Given that this is a cross-sectional study, no causality can be inferred. Thus, a longitudinal design would also ensure a better understanding of the relationships here inferred. Furthermore, future studies should focus on self-blame coping to understand how this strategy could be targeted in intervention projects designed explicitly for LGB youth. Regarding personal growth, LGB individuals could learn more positive and adaptive strategies to soften the effects of perceived discrimination on their mental health.

This study shed light on protective factors that may contribute to the resilience of LGB youth when facing perceived discrimination. Although the LGB participants in this study manifested a form of resilience in the face of perceived discrimination (a result that could have been due to the instruments used), LGB individuals should not need to carry the burden of dealing with social violence. Thus, major investments need to be made to prevent violence. These findings show that professionals who work with LGB youth (e.g., teachers, clinicians, psychologists) must target the propensity for these individuals to blame themselves after discriminatory events and, preferably, increase the use of positive reframing coping strategies, while also looking for LGBT-specific support or integration in LGBT communities. It should be noted that, despite this need to invest in intrapersonal skills, efforts to improve contextual and systemic conditions (such as marriage equality) should not be neglected, since the literature also stresses their importance. In addition to these strategies, prevention should not be overlooked, as work must be done to prevent discrimination both in institutions and interpersonal relationships.

\section{References}

Almeida, J., Johnson, R. M., Corliss, H. L., Molnar, B. E., \& Azrael, D. (2009). Emotional distress among LGBT youth: The influence of perceived discrimination based on sexual orientation. Journal of Youth and Adolescence, 38(7), 1001-1014. https://doi.org/10.1007/s10964$\underline{009-9397-9}$

Baams, L., Grossman, A. H., \& Russell, S. T. (2015). Minority stress and mechanisms of risk for depression and suicidal ideation among lesbian, gay, and bisexual youth. Developmental Psychology, 51(5), 688-696. https://doi.org/10.1037/a0038994

Berlan, E. D., Corliss, H. L., Field, A. E., Goodman, E., \& Austin, S. B. (2010). Sexual orientation and bullying among adolescents in the growing up today study. Journal of Adolescent Health, 46(4), 366-371. https://doi.org/10.1016/j.jadohealth.2009.10.015

Bontempo, D. E., \& D'Augelli, A. R. (2002). Effects of at-school victimization and sexual orientation on lesbian, gay, or bisexual youths' health risk behavior. Journal of Adolescent Health, 30(5), 364-374. https://doi.org/10.1016/S1054-139X(01)00415-3

Bucchianeri, M. M., Eisenberg, M. E., Wall, M. M., Piran, N., \& Neumark-Sztainer, D. (2014). Multiple types of harassment: Associations with emotional well-being and unhealthy behaviors in adolescents. Journal of Adolescent Health, 54(6), 724-729. https://doi.org/10.1016/j.jadohealth.2013.10.205

Bucchianeri, M. M., Gower, A. L., McMorris, B. J., \& Eisenberg, M. E. (2016). Youth experiences with multiple types of prejudice-based harassment. Journal of Adolescence, 51, 68-75. https://doi.org/10.1016/j.adolescence.2016.05.012

Carneiro, N. S. (2006). Ser, pertencer e participar: construção da identidade homossexual, redes de apoio e participação comunitária [Being, belonging and participating: Building the homosexual identity, networks of support and community participation; Doctoral dissertation, Faculdade de Psicologia e Ciências da Educação, Universidade do Porto]. U. Porto Sigarra. https://repositorioaberto.up.pt/handle/10216/56666

Carver, C. S. (1997). You want to measure coping but your protocol's too long: Consider the Brief COPE. International Journal of Behavioral Medicine, 4(1), 92-100. https://doi.org/10.1207/s15327558ijbm0401_6

Carver, C. S., \& Connor-Smith, J. (2010). Personality and coping. Annual Review of Psychology, 61, 679-704. https://doi.org/10.1146/annurev.psych.093008.100352

Coimbra, S., \& Fontaine, A. M. (2015). Resiliência e habilidades sociais: reflexões conceituais e práticas para uma nova geração [Resilience and social skills: Conceptual and practical considerations for a new generation]. In Z. A. P. Del Prette, A. B. Soares, C. de S. Pereira-Guizzo, M. F. Wagner, \& V. B. R. Leme (Orgs.), Habilidades sociais: diálogos e intercâmbios sobre pesquisa e prática [Social skills: Dialogues and exchanges on research and practice] (pp. 186-220). Sinopsys.

Compas, B. E., Jaser, S. S., Dunn, M. J., \& Rodriguez, E. M. (2012). Coping with chronic illness in childhood and adolescence. Annual Review of Clinical Psychology, 8, 455-480. https://doi.org/10.1146/annurev-clinpsy-032511-143108 
Costa Jr., P. T., Terracciano, A., \& McCrae, R. R. (2001). Gender differences in personality traits across cultures: Robust and surprising findings. Journal of Personality and Social Psychology, 81(2), 322-331. https://doi.org/10.1037/0022-3514.81.2.322

D'Augelli, A. R. (2002). Mental health problems among lesbian, gay, and bisexual youths ages 14 to 21. Clinical Child Psychology and Psychiatry, 7(3), 433-456. https://doi.org/10.1177/1359104502007003010

D'haese, L., Dewaele, A., \& Van Houtte, M. (2015). Coping with antigay violence: In-depth interviews with Flemish LGB adults. The Journal of Sex Research, 52(8), 912-923. https://doi.org/10.1080/00224499.2014.990554

Eisenberg, M. E., \& Resnick, M. D. (2006). Suicidality among gay, lesbian and bisexual youth: The role of protective factors. Journal of Adolescent Health, 39(5), 662-668. https://doi.org/10.1016/j.jadohealth.2006.04.024

Espelage, D. L., Aragon, S. R., Birkett, M., \& Koenig, B. W. (2008). Homophobic teasing, psychological outcomes, and sexual orientation among high school students: What influence do parents and schools have? School Psychology Review, 37(2), $202-216$. https://www.tandfonline.com/doi/abs/10.1080/02796015.2008.12087894

Fedewa, A. L., \& Ahn, S. (2011). The effects of bullying and peer victimization on sexual-minority and heterosexual youths: A quantitative meta-analysis of the literature. Journal of GLBT Family Studies, 7(4), 398-418. https://doi.org/10.1080/1550428X.2011.592968

Feinstein, B. A., Goldfried, M. R., \& Davila, J. (2012). The relationship between experiences of discrimination and mental health among lesbians and gay men: An examination of internalized homonegativity and rejection sensitivity as potential mechanisms. Journal of Consulting and Clinical Psychology, 80(5), 917-927. https://doi.org/10.1037/a0029425

Freitas, D. F., Coimbra, S., \& Fontaine, A. M. (2017). Resilience in LGB youths: A systematic review of protection mechanisms. Paidéia (Ribeirão Preto), 27(66), 69-79. https://doi.org/10.1590/1982-43272766201709

Freitas, D. F., Coimbra, S., Fontaine, A. M., \& Marturano, E. M. (2017). Mecanismos de proteção perante a vitimização por pares e a discriminação [Protection mechanisms in the face of peer victimization and discrimination]. Psicologia (Associação Portuguesa de Psicologia), 31(2), 25-46. https://doi.org/10.17575/rpsicol.v31i2.1152

Freitas, D. F., Coimbra, S., Marturano, E. M., \& Fontaine, A. M. (2015). Adaptação da Escala de Discriminação Quotidiana para jovens portugueses [Adaptation of the Everyday Discrimination Scale to Portuguese youth]. Psicologia: Reflexão e Crítica, 28(4), $708-717$. https://doi.org/10.1590/1678-7153.201528408

Frost, D. M., Lehavot, K., \& Meyer, I. H. (2015). Minority stress and physical health among sexual minority individuals. Journal of Behavioral Medicine, 38(1), 1-8. https://doi.org/10.1007/s10865-013-9523-8

Gato, J., Carneiro, N. S., \& Fontaine, A. M. (2011). Contributo para uma revisitação histórica e crítica do preconceito contra as pessoas não heterossexuais [Contribution to a historical and critical review of prejudice against non-heterosexual persons]. Crítica $e$ Sociedade, 1(1), 139-167. http://www.seer.ufu.br/index.php/criticasociedade/article/view/12542

Graham, S., \& Juvonen, J. (1998). Self-blame and peer victimization in middle school: An attributional analysis. Developmental Psychology, 34(3), 587-599. https://doi.org/10.1037/0012-1649.34.3.587

Hatzenbuehler, M. L. (2009). How does sexual minority stigma "get under the skin"? A psychological mediation framework. Psychological Bulletin, 135(5), 707-730. https://doi.org/10.1037/a0016441

Hayes, A. F. (2013). Introduction to mediation, moderation, and conditional process analysis: A regression-based approach. Guilford Press.

Hayes, A. F. (2015). An index and test of linear moderated mediation. Multivariate Behavioral Research, 50(1), 1-22. https://doi.org/10.1080/00273171.2014.962683

Katz-Wise, S. L., \& Hyde, J. S. (2012). Victimization experiences of lesbian, gay, and bisexual individuals: A meta-analysis. The Journal of Sex Research, 49(2-3), 142-167. https://doi.org/10.1080/00224499.2011.637247

Kaysen, D. L., Kulesza, M., Balsam, K. F., Rhew, I. C., Blayney, J. A., Lehavot, K., \& Hughes, T. L. (2014). Coping as a mediator of internalized homophobia and psychological distress among young adult sexual minority women. Psychology of Sexual Orientation and Gender Diversity, 1(3), 225-233. https://doi.org/10.1037/sgd0000045

King, M., Semlyen, J., Tai, S. S., Killaspy, H., Osborn, D., Popelyuk, D., \& Nazareth, I. (2008). A systematic review of mental disorder, suicide, and deliberate self harm in lesbian, gay and bisexual people. BMC Psychiatry, 8, Article 70. https://doi.org/10.1186/1471-244X-8-70

Kuyper, L., de Roos, S., Iedema, J., \& Stevens, G. (2016). Growing up with the right to marry: Sexual attraction, substance use, and well-being of Dutch adolescents. Journal of Adolescent Health, 59(3), 276-282. https://doi.org/10.1016/j.jadohealth.2016.05.010

Kwon, P. (2013). Resilience in lesbian, gay, and bisexual individuals. Personality and Social Psychology Review, 17(4), 371-383. https://doi.org/10.1177/1088868313490248

Kwon, P., \& Hugelshofer, D. S. (2010). The protective role of hope for lesbian, gay, and bisexual individuals facing a hostile workplace climate. Journal of Gay \& Lesbian Mental Health, 14(1), 3-18. https://doi.org/10.1080/19359700903408914

Lira, A. N., \& Morais, N. A. (2018). Resilience in lesbian, gay, and bisexual (LGB) populations: An integrative literature review. Sexuality Research and Social Policy, 15(3), 272-282. https://doi.org/10.1007/s13178-017-0285-x

Luthar, S. S., Cicchetti, D., \& Becker, B. (2000). The construct of resilience: A critical evaluation and guidelines for future work. Child Development, 71(3), 543-562. https://doi.org/10.1111/1467-8624.00164

Marques, S. C., Pais-Ribeiro, J. L., \& Lopez, S. J. (2011). Use of the "Mental Health Inventory - 5" with Portuguese 10-15 years old. The Spanish Journal of Psychology, 14(1), 478-485. https://doi.org/10.5209/rev_SJOP.2011.v14.n1.43

Marshal, M. P., Dietz, L. J., Friedman, M. S., Stall, R., Smith, H. A., McGinley, J., Thom, B., Murray, P., D’Augelli, A., \& Brent, D. A. (2011). Suicidality and depression disparities between sexual minority and heterosexual youth: A meta-analytic review. Journal of Adolescent Health, 49(2), 115-123. https://doi.org/10.1016/j.jadohealth.2011.02.005

Masten, A. S. (2001). Ordinary magic: Resilience processes in development. American Psychologist, 56(3), 227-238. https://doi.org/10.1037/0003066X.56.3.227

Masten, A. S. (2014). Ordinary magic: Resilience in development. Guilford Press.

Masten, A. S., \& Tellegen, A. (2012). Resilience in developmental psychopathology: Contributions of the Project Competence Longitudinal Study. Development and Psychopathology, 24(2), 345-361. https://doi.org/10.1017/S095457941200003X

McDougall, P., \& Vaillancourt, T. (2015). Long-term adult outcomes of peer victimization in childhood and adolescence: Pathways to adjustment and maladjustment. American Psychologist, 70(4), 300-310. https://doi.org/10.1037/a0039174

McLaughlin, K. A., Hatzenbuehler, M. L., \& Keyes, K. M. (2010). Responses to discrimination and psychiatric disorders among Black, Hispanic, female, and lesbian, gay, and bisexual individuals. American Journal of Public Health, 100(8), 1477-1484. https://doi.org/10.2105/AJPH.2009.181586

Meyer, I. H. (2003). Prejudice, social stress, and mental health in lesbian, gay, and bisexual populations: Conceptual issues and research evidence. Psychological Bulletin, 129(5), 674-697. https://doi.org/10.1037/0033-2909.129.5.674 
Meyer, I. H. (2015). Resilience in the study of minority stress and health of sexual and gender minorities. Psychology of Sexual Orientation and Gender Diversity, 2(3), 209-213. https://doi.org/10.1037/sgd0000132

Mongelli, F., Perrone, D., Balducci, J., Sacchetti, A., Ferrari, S., Mattei, G., \& Galeazzi, G. M. (2019). Minority stress and mental health among LGBT populations: An update on the evidence. Minerva Psichiatrica, 60(1), 27-50. https://doi.org/10.23736/S03911772.18.01995-7

Murdock, T. B., \& Bolch, M. B. (2005). Risk and protective factors for poor school adjustment in lesbian, gay, and bisexual (LGB) high school youth: Variable and person-centered analyses. Psychology in the Schools, 42(2), 159-172. https://doi.org/10.1002/pits.20054

Mustanski, B., Andrews, R., \& Puckett, J. A. (2016). The effects of cumulative victimization in mental health among lesbian, gay, bisexual, and transgender adolescents and young adults. American Journal of Public Health, 106(3), 527-533. https://doi.org/10.2105/AJPH.2015.302976

Pais Ribeiro, J. L., \& Rodrigues, A. P. (2004). Questões acerca do coping: a propósito do estudo de adaptação do Brief COPE [Some questions about coping: The study of the Portuguese adaptation of the Brief COPE]. Psicologia, Saúde \& Doenças, 5, 3-15. http://www.scielo.mec.pt/scielo.php?script=sci_arttext\&pid=S1645-00862004000100001

Pedroso-Lima, M., Magalhães, E., Salgueira, A., Gonzalez, A. -J., Costal, J. J., Costa, M. J., \& Costa, P. (2014). A versão portuguesa do NEO-FFI: Caracterização em função da idade, género e escolaridade [The Portuguese version of the NEO FFI: age, gender and education characterization]. Psicologia (Associação Portuguesa de Psicologia), 28(2), 1-10. http://www.scielo.mec.pt/scielo.php?script=sci_arttext\&pid=S0874-20492014000200001

Plöderl, M., \& Tremblay, P. (2015). Mental health of sexual minorities. A systematic review. International Review of Psychiatry, 27(5), 367-385. https://doi.org/10.3109/09540261.2015.1083949

Russell, S. T., Sinclair, K. O., Poteat, V. P., \& Koenig, B. W. (2012). Adolescent health and harassment based on discriminatory bias. American Journal of Public Health, 102(3), 493-495. https://doi.org/10.2105/AJPH.2011.300430

Russell, S. T., Toomey, R. B., Ryan, C., \& Diaz, R. M. (2014). Being out at school: The implications for school victimization and young adult adjustment. American Journal of Orthopsychiatry, 84(6), 635-643. https://doi.org/10.1037/ort0000037

Rutter, M., Caspi, A., \& Moffitt, T. E. (2003). Using sex differences in psychopathology to study causal mechanisms: Unifying issues and research strategies. Journal of Child Psychology and Psychiatry, 44(8), 1092-1115. https://doi.org/10.1111/1469-7610.00194

Saewyc, E. M. (2011). Research on adolescent sexual orientation: Development, health disparities, stigma, and resilience. Journal of Research on Adolescence, 21(1), 256-272. https://doi.org/10.1111/j.1532-7795.2010.00727.x

Sanders, E. K., \& Chalk, H. M. (2016). Predictors of psychological outcomes in nonheterosexual individuals. Journal of Psychological Research, 21(2), 100-110. https://psycnet.apa.org/record/2016-26343-005

Schacter, H. L., White, S. J., Chang, V. Y., \& Juvonen, J. (2015). "Why me?": Characterological self-blame and continued victimization in the first year of middle school. Journal of Clinical Child \& Adolescent Psychology, 44(3), 446-455. https://doi.org/10.1080/15374416.2013.865194

Schmitt, M. T., Branscombe, N. R., Postmes, T., \& Garcia, A. (2014). The consequences of perceived discrimination for psychological well-being: A meta-analytic review. Psychological Bulletin, 140(4), 921-948. https://doi.org/10.1037/a0035754

Toomey, R. B., Ryan, C., Diaz, R. M., \& Russell, S. T. (2018). Coping with sexual orientation-related minority stress. Journal of Homosexuality, 65(4), 484-500. https://doi.org/10.1080/00918369.2017.1321888

Veit, C. T., \& Ware, J. E. (1983). The structure of psychological distress and well-being in general populations. Journal of Consulting and Clinical Psychology, 51(5), 730-742. https://doi.org/10.1037/0022-006X.51.5.730

Werner, E. E., \& Smith, R. S. (1992). Overcoming the odds: High risk children from birth to adulthood. Cornell University Press.

Werner, E. E., \& Smith, R. S. (2001) Journeys from childhood to the midlife: Risk, resilience, and recovery. Cornell University Press.

Williams, D. R., Yu, Y., Jackson, J. S., \& Anderson, N. B. (1997). Racial differences in physical and mental health: Socio-economic status, stress and discrimination. Journal of Health Psychology, 2(3), 335-351. https://doi.org/10.1177/135910539700200305

Williams, T., Connolly, J., Pepler, D., \& Craig, W. (2005). Peer victimization, social support, and psychosocial adjustment of sexual minority adolescents. Journal of Youth and Adolescence, 34(5), 471-482. https://doi.org/10.1007/s10964-005-7264-x

Woodford, M. R., Han, Y., Craig, S., Lim, C., \& Matney, M. M. (2014). Discrimination and mental health among sexual minority college students: The type and form of discrimination does matter. Journal of Gay \& Lesbian Mental Health, 18(2), 142-163. https://doi.org/10.1080/19359705.2013.833882

Fecha de recepción: Agosto de 2018.

Fecha de aceptación: Mayo de 2020. 